\title{
A DIFERENÇA SALARIAL NAS INDÚSTRIAS BRASILEIRAS: DESDOBRAMENTOS NO ESPAÇO GEOGRÁFICO
}

\author{
Ana Carolina dos Santos Marques \\ Universidade Estadual Paulista "Júlio de Mesquita Filho", Faculdade de Ciências e Tecnologia, \\ Mestranda em Geografia, Presidente Prudente, SP, Brasil \\ anaaa0@hotmail.com \\ Claudio Roberto Bragueto \\ Universidade Estadual de Londrina, Professor Adjunto no Departamento de Geociências, \\ Londrina, PR, Brasil \\ bragueto@uel.br
}

\begin{abstract}
RESUMO
A indústria tem papel importante na produção do espaço e na geração de riqueza social, compreender suas dinâmicas é importante para entender o arranjo espacial e seus desdobramentos no território. A renda média do pessoal ocupado caracteriza-se como uma destas dinâmicas essenciais para compreensão da organização espacial brasileira, produzindo impactos socioeconômicos na população brasileira. Desta forma, este artigo objetiva verificar a diferença salarial no setor industrial nas mesorregiões geográficas relevantes, de acordo com a intensidade tecnológica, sendo o recorte temporal os anos de 1995 a 2015. Para tanto, foram realizados levantamentos bibliográficos e do banco de dados do Ministério do Trabalho e Emprego - RAIS, além do mapeamento das mesorregiões geográficas relevantes em termos de pessoal ocupado. Os resultados apontam que o período em questão foi marcado por uma desconcentração concentrada, em que as mesorregiões de maior crescimento e maior número de pessoal ocupado estão localizadas em sua maioria, no Centro-Sul do Brasil e que a desigualdade salarial brasileira é constituída pelas rendas médias menores centralizadas na região Nordeste e pelas remunerações maiores no Centro-Sul do país. Além disso, houve uma queda de renda média generalizada, tanto em termos regionais quanto nos ramos industriais de maior ou menor intensidade tecnológica.
\end{abstract}

Palavras-chave: indústria; renda média; pessoal ocupado; diferença salarial; mesorregiões geográficas.

\section{THE WAGE GAP IN BRAZILIAN INDUSTRIES: UNFOLDING ON GEOGRAPHICAL SPACE}

\begin{abstract}
Industry has an important role in the space production and in social wealth generation, comprehend its dynamics is important to understand the space arrangement and its unfolding on territory. The average income of the busy people characterize itself as one of these essential dynamics to comprehend the brazilian space organization, producing socioeconomic impacts in the brazilian population. Thus, this paper goal to verify the wage gap in the industrial sector in relevant geographical mesoregions, according to technological intensity, using the years from 1995 to 2015 as time frame. Therefore, bibliographical and Ministry of Labor and Employment - RAIS surveys were performed, besides the mapping of the relevant geographical mesoregions in terms of busy people. The results point that the period concerned was determined by a concentrated deconcentration, wherein the mesoregions with higher growing and bigger amount of busy people are localized mostly, in South-Center of Brazil and that brazilian wage inequality is constituted by low average incomes centralized in Northeast region and by higher remuneration in country South-Center. Besides, there was a generalized falling of average income, both in regional terms as in industrial branches of higher or lower technological intensity. Keywords: industry; average income; busy people; wage gap; geographical mesoregions.
\end{abstract}




\section{INTRODUÇÃO}

O presente artigo objetiva verificar a diferença salarial no setor industrial nas mesorregiões geográficas relevantes ao estudo no período de 1995 a 2015, de acordo com a intensidade tecnológica das indústrias.

Há um destaque considerável para a esfera da gestão, da circulação e do consumo, porém a indústria tem papel importante na produção do espaço e na geração de riqueza social. Desta forma, é essencial compreender as dinâmicas industriais para entender o arranjo espacial e os desdobramentos da industria no território.

A desigualdade salarial caracteriza-se como um tema muito estudado por pesquisadores de diferentes áreas do conhecimento. Aspectos como educação, gênero e cor são abordados para explicar essa desigualdade, porém no setor industrial é preciso considerar também a região geográfica na qual os empregados e a indústria, além da intensidade tecnológica desta e dos processos de concentração e de desconcentração espacial, fatores que também influenciam no nível salarial.

O processo de concentração e desconcentração espacial da indústria pelo território brasileiro também influencia na renda média do pessoal ocupado, a alocação e a realocação dos trabalhadores são aspectos que modificam seus salários e determinam os custos da empresa, que geralmente migram em busca da minimização dos gastos.

As perguntas de investigação que motivaram a pesquisa são: Há uma desigualdade salarial no setor industrial brasileiro? Quais as regiões que se destacam em relação à renda média do pessoal ocupado no setor industrial? Quais fatores contribuem para a diferença salarial no setor industrial?

Como procedimentos metodológicos, utilizou-se como recorte espacial as 96 mesorregiões geográficas brasileiras relevantes estabelecidas por Bragueto e Marques (2017), em que foram selecionadas as mesorregiões que possuíam pessoal ocupado superior a 10.000 no setor industrial.

O recorte temporal aplicado foi o período de 1995 a 2015, uma vez que a partir de meados da década de 1990 há um processo de desconcentração espacial da indústria brasileira. A intensidade tecnológica das indústrias também foi considerada, para isso, utilizou-se os subsetores do IBGE, sendo de menor intensidade tecnológica os seguintes: Extrativa mineral, Produção mineral não metálico, Indústria metalúrgica, Madeira e mobiliário, Papel e gráfica, Borracha, fumo e couros, Indústria calçados, Indústria têxtil e Alimentos e bebidas. Enquanto os de maior intensidade tecnológica tem-se os setores: Indústria mecânica, Elétrico e Comunicação, Material de transporte e Indústria química.

Os dados utilizados foram a quantidade de vínculos ativos nas indústrias das mesorregiões e a renda média dos trabalhadores, obtidos por meio do banco de dados do Ministério do Trabalho e Emprego - RAIS (Relação Anual de Informações Sociais) (BRASIL, 2018). Foram estabelecidas categorias para a renda média anual, saber: até 1,5 salários mínimos, de 1,51 a 3,0 salários mínimos, de 3,01 a 7,0 salários mínimos e acima de 7,01 salários mínimos. Além disso, os dados representam o percentual de pessoal ocupado de cada mesorregião que recebem determina faixa de renda média. Em seguida, foram elaboradas cartas temáticas a fim de representar cartograficamente as informações coletadas.

A primeira parte do trabalho é dedicada a discutir a reestruturação produtiva no Brasil e a segunda parte apresenta os resultados obtidos por meio da pesquisa de dados e da elaboração de mapas que espacializam a diferença salarial brasileira.

\section{REESTRUTURAÇÃO PRODUTIVA NO BRASIL}

Ao discutir quantidade de pessoal ocupado nas indústrias brasileiras é fundamental abordar a reestruturação produtiva no país, pois as transformações no regime de acumulação e nos modos de regulação econômica possuem impacto direto nas dinâmicas do espaço geográfico e nas condições de trabalho. 
De acordo com Lencioni (2003), a palavra produtiva trata-se de uma adjetivação que se refere a produção como elemento determinante da reestruturação e ainda aponta que nos últimos anos temos assistido uma reestruturação do processo de reprodução capitalista.

Deste modo, a reestruturação produtiva refere-se a uma mudança na estrutura produtiva dominante, porém esse processo não acontece repentinamente, ele é resultado de diversos fatores e compostos por contradições, conflitos e tensões, como destaca Soja (1993):

\begin{abstract}
[...] a reestruturação, em seu sentido mais amplo, transmite a noção de uma "freada", senão de uma ruptura nas tendências seculares, e de uma mudança em direção a uma ordem e uma configuração significativamente diferentes da vida social, econômica e política. Evoca, pois, uma combinação seqüencial de desmoronamento e reconstrução, de desconstrução e tentativa de reconstituição, proveniente de algumas deficiências ou perturbações nos sistemas de pensamento e ação aceitos. A antiga ordem está suficientemente esgarçada para impedir os remendos adaptativos convencionais e exigir, em vez deles, uma expressiva mudança estrutural (SOJA, 1993, p. 193).
\end{abstract}

As estruturas dessa ordem, de acordo com Lencioni (1998), não são fixas nem estáveis. Para a autora é um erro comum pensar que reestruturação é caracterizada pela sobreposição de uma estrutura sobre a anterior, substituindo-a completamente. Porém, na realidade, as estruturas possuem um equilíbrio provisório que, quando abalado, resulta em um processo de estruturaçãodesestruturação-reestruturação, constituindo um movimento único.

A reestruturação produtiva se deu por meio da transição do fordismo para a acumulação flexível. De acordo com Harvey (1992), o período de expansão do pós-guerra, que compreende nos anos de 1945 a 1973, foi caracterizado pelo regime de acumulação fordista-keynesiano, baseado na adaptação do consumo de massa aos ganhos de produtividade.

A acumulação flexível, segundo Harvey (1992):

[...] envolve rápidas mudanças dos padrões do desenvolvimento desigual, tanto entre setores como entre regiões geográficas, criando, por exemplo, um vasto movimento no emprego no chamado 'setor de serviços', bem como conjuntos industriais completamente novos em regiões até então subdesenvolvidas [...] Ela também envolve um novo movimento que chamarei de "compressão do espaço-tempo" no mundo capitalista - os horizontes temporais da tomada de decisões privada e pública se estreitam, enquanto a comunicação via satélite e a queda dos custos de transporte possibilitaram cada vez mais a difusão imediata dessas decisões num espaço cada vez mais amplo e variegado (HARVEY, 1992, p. 140).

O regime de acumulação flexível é marcado pela especialização flexível, sistema de produção verticalmente desintegrado e ausência de hierarquias rígidas. Além disso, é constituído por uma mobilidade acelerada do capital que facilita sua busca por superlucros setoriais (SOJA, 1993, p. 208).

O fordismo entra em crise, de acordo com Lipietz e Leborgne (1988), devido, primeiramente, a uma crise latente do paradigma industrial, somada a desaceleração da produtividade e crescimento da relação capital/produto, que conduziu a uma queda da lucratividade nos anos de 1960. A reação dos empresários e do Estado levou ainda a uma crise do emprego e do Estadoprovidência e a internacionalização e estagnação dos rendimentos detonaram a crise "do lado da demanda" no fim dos anos de 1970.

Assim, essa crise se evidenciou na década de 1970 desencadeando um longo processo de reestruturação dos setores econômicos:

Como resultado, governos e empresas adotaram medidas de adaptação intensificando, nas suas esferas de atuação, as mudanças regulatórias, tecnológicas, organizacionais e produtivas que, combinadas, acabaram por reorganizar as relações de poder, produção, gerência e as formas de organização do trabalho, desencadeando uma onda de reestruturações para superar as dificuldades geradas pela crise do fordismo [...] No Brasil, a

$\begin{array}{lllll}\text { Caminhos de Geografia } & \text { Uberlândia - MG } & \text { v. 20, n. } 70 & \text { Junho/2019 } & \text { p. 276-291 Página } 278\end{array}$


reestruturação do setor produtivo e a introdução de práticas da acumulação flexível passaram a se intensificar a partir da década de 1980, como resultados do processo de adoção das deliberações dos organismos multilaterais que incluíam a abertura econômica, a desregulamentação do mercado nacional, o controle dos gastos públicos, entre outras medidas, fundamentadas na política de cunho neoliberal. Esses ajustes levaram ao constrangimento do Estado diante da crise interna (crise da dívida e da moeda) e externa (crise do fordismo) que, combinadas com a reestruturação produtiva, agravaram ainda mais o quadro de estagflação, crise social e desemprego estrutural (SANTOS, 2015, p. 202-203).

Deste modo, a reestruturação produtiva modifica diretamente as dinâmicas relacionadas ao emprego e ao pessoal ocupado nas indústrias. No regime de acumulação fordista, o aumento da produtividade foi expressivo, assim o comportamento dos trabalhadores era direcionado a partir de princípios gestores, separando o trabalho manual do trabalho intelectual e levando à máxima eficiência produtiva dos recursos humanos e dos operários. Ocorreram novas formas institucionais de garantia de crescimento de salário direto, como legislação trabalhista e salário mínimo; e indireto, como garantias sociais do Estado-previdência (SANTOS, 2015).

No modo de regulação de acumulação flexível, as relações de trabalho foram profundamente modificadas gerando resistência da classe trabalhadora. A reestruturação buscava diminuir os custos de produção, sendo necessárias novas formas de relações trabalhistas, o processo de trabalho passou a exigir poucas habilidades do trabalhador e diversos direitos foram perdidos, por exemplo os custos com salários indiretos, como previdência e seguridade social (SANTOS, 2015).

Segundo Santos (2015), novas formas de contratação foram criadas, como subcontratação, terceirização e contratação por tempo limitado ou de trabalho parcial e as garantias de emprego foram praticamente extintas.

Com os aspectos da produção cada vez mais flexíveis, são concebidas novas configurações no interior da empresa e no mercado que ela atua a partir de estratégias competitivas passíveis de adaptação, de acordo com as oscilações do mercado. Assim, as empresas têm a capacidade de agir sobre seu quadro de contratados, diminuindo ou aumentando seu número, ou sobre as suas funções, com a flexibilidade funcional que vem sendo cada vez mais exigida do trabalhador (SANTOS, 2015, p. 219).

Essa insegurança provocada por estas formas é vantajosa para as empresas na medida em que permite controlar a quantidade de pessoal ocupado de acordo com a necessidade, reduzindo custos em períodos de menor produção. Há ainda, uma diminuição da oferta de emprego devido à implantação crescente de novas tecnologias que passam a realizar atividades que antes necessitavam de diversos trabalhadores.

A importância do poder sindical nas empresas também é drasticamente reduzida. Isto porque 0 mercado de trabalho tornou-se mais segmentado e flexível e ocorreu o aumento da negociação entre empresa e trabalhador, perdendo-se a noção de negociação coletiva e de luta pelos direitos trabalhistas. Além disso, a competitividade entre trabalhadores é aprofundada, os contratos temporários são utilizados como estratégias para que o trabalhador fixo de engaje mais por manter sua carreira, temendo a demissão (SANTOS, 2015). Portanto, as relações de trabalho passam a ser crescentemente precarizadas.

Além da reestruturação, a mobilidade do capital advinda desse processo possui implicações diretas no salário do pessoal ocupado das indústrias. A localização geográfica destas influencia na quantidade necessária de trabalhadores, no salário destes, na intensidade tecnológica, nas condições de trabalho e no ramo industrial de atuação.

De acordo com Harvey (1992), a mobilidade geográfica do capital é vantajosa para a reprodução do capital e para o controle da mão de obra:

[...] O aumento da competição em condições de crise coagiu os capitalistas a darem muito mais atenção às vantagens localizacionais relativas, 


\begin{abstract}
precisamente porque a diminuição de barreiras espaciais dá aos capitalistas o poder de explorar, com bom proveito, minúsculas diferenciações espaciais. Pequenas diferenças naquilo que o espaço contém em termos de oferta de trabalho, recursos, infra-estruturas etc. assumem crescente importância. $\mathrm{O}$ domínio superior do espaço é uma arma ainda mais poderosa na luta de classes [...]. A mobilidade geográfica e a descentralização são usadas contra um poder sindical que se concentrava tradicionalmente nas fábricas de produção em massa. A fuga de capitais, a desindustrialização de algumas regiões e a industrialização de outras e a destruição de comunidades operárias tradicionais como bases de poder na luta de classes se tornaram o pivô na transformação espacial sob condições de acumulação mais flexíveis (HARVEY, 1992, p.265).
\end{abstract}

Intrínseca à mobilidade do capital há a concentração e desconcentração das indústrias no espaço geográfico. Segundo Firkowski (2005), devem ser compreendidas como duas faces de um mesmo processo, como em uma relação dialética em que ao mesmo tempo que atividades produtivas se desconcentram territorialmente, inserindo novos lugares ao processo produtivo, também há uma grande concentraçãoem poucos lugares privilegiados e que concentram geralmente atividades relacionadas à decisão, gestão, produção de inovação e informação.

Em relação ao processo de desconcentração que influencia nos salários dos trabalhadores, é relevante pontuar que, de acordo com a bibliografia, destacam-se dois períodos: o primeiro, que pode ser denominado de auge do processo de desconcentração, o qual compreende os anos de 1970 a 1985; e o segundo, em que ocorre a inflexão do processo com a crise econômica, compreendendo os anos de 1985 até meados de 1990 (AZZONI, 1985; DINIZ, 1995; DINIZ e CROCCO, 1996; CANO, 1997; TINOCO, 2001; BRAGUETO, 2007). A partir de meados de 1990, o debate volta à tona, pois, estaria havendo uma retomada do processo de desconcentração, caracterizando um terceiro período como apontam Firkowski (2001) e Tinoco (2001).

A intensidade tecnológica dos ramos industriais constitui-se um elemento decisivo na interpretação do processo de concentração e desconcentração industrial. Tinoco (2001) destaca que há a coexistência de padrões simultâneos de desenvolvimento industrial, desta forma coexistem o padrão antigo e clássico, fordista, e o padrão novo, pós-fordista com ênfase nos setores de alta tecnologia. Deste modo, um período é caracterizado por requisitos locacionais clássicos e o outro, pela coexistência desse padrão somado aos de localização modernos, além de sofrer influência de substratos econômicos distintos, conjuntos, arranjos institucionais e padrões de desenvolvimento diferenciados.

Outro elemento que é essencial para compreender a dinâmica industrial brasileira recente são as condições gerais de produção, que viabilizam o funcionamento das empresas. Essas condições não estão distribuídas de forma uniforme, em especial aquelas mais diretamente vinculadas com as indústrias de maior intensidade tecnológica, o que consequentemente é uma das causas da desigual distribuição espacial da indústria pelo território nacional, assim como da dispersão diferenciada da indústria de maior intensidade tecnológica em relação àquelas mais tradicionais, de menor intensidade tecnológica.

De acordo com Bragueto e Marques (2017), nos anos posteriores a 1994, houve um período de desconcentração do pessoal ocupado na indústria, porém trata-se de uma desconcentração concentrada, em que as mesorregiões que apresentaram maior crescimento industrial e receberam maiores investimentos estão, em sua grande maioria, localizadas no Centro-Sul, contribuindo para a manutenção da desigual distribuição espacial da indústria pelo Brasil.

A partir destes pressupostos, a diferença salarial na indústria pode ser explicada com base em todos os processos citados, tais como: a reestruturação produtiva no sentido de que com a acumulação flexível as condições e relações de trabalho foram modificadas, a mobilidade do capital, os processos de concentração e de desconcentração que "definem" a localização geográfica das indústrias, as condições de trabalho e a intensidade tecnológica que define os os salários do pessoal ocupado, ou seja, quanto mais a intensidade, maiores serão as remunerações. 


\section{A DIFERENÇA SALARIAL NAS INDÚSTRIAS BRASILEIRAS}

Objetivando verificar e compreender a diferença salarial no setor industrial nas mesorregiões industriais relevantes no período de 1995 a 2015, torna-se essencial investigar a renda média dos trabalhadores e em quais mesorregiões e regiões brasileiras estão alocados os empregados que recebem rendas maiores e menores, além da intensidade tecnológica das indústrias em que se concentram.

\section{INDÚSTRIAS DE MAIOR INTENSIDADE TECNOLÓGICA - 1995}

Conforme a Figura 1, que representa os trabalhadores das indústrias de maior intensidade tecnológica em 1995, constata-se que nas 26 mesorregiões relevantes localizadas na região Nordeste, a maior parte delas concentrava trabalhadores nas faixas de renda menores. Havia 20 mesorregiões apresentando a maior parte dos trabalhadores nas faixas de renda menores, até 3 salários mínimos, com destaque para o Agreste Sergipano, em que todos os trabalhadores estavam na faixa de renda de até 1,5 salários mínimos e na Central Potiguar, com $80 \%$ deles. Por outro lado, nas faixas de renda superiores, isto é, acima de 3,01 salários mínimos, apenas 6 mesorregiões apresentavam a maior parte dos trabalhadores nestas faixas de renda. As principais exceções eram o Leste Alagoano e a Metropolitana de Salvador, em que há o predomínio dos trabalhadores que recebiam acima de 7,01 salários mínimos, 48\% e 64\%, respectivamente.

As faixas de renda menores predominavam nas mesorregiões, no entanto, no total dos trabalhadores do Nordeste somente $34 \%$ recebiam até 3 salários mínimos e $66 \%$ se enquadravam nas faixas de rendas superiores a estes valores. Esta inversão (verificada em outras regiões brasileiras, como a Norte) ocorre em função das poucas mesorregiões em que há predomínio dos trabalhadores melhores remunerados serem regiões com maior concentração industrial, com destaque para as capitais estaduais e as regiões metropolitanas. Portanto, estas mesorregiões relevantes com maior importância são as que adquirem maior destaque na renda média dos trabalhadores nordestinos.

Em outras palavras, existem indústrias de maior intensidade tecnológica nas mesorregiões com menor importância industrial, porém, geralmente são empresas menores que, embora sejam dos ramos industriais aqui classificados como de maior intensidade tecnológica, de fato não possuem alta tecnologia e os trabalhadores apresentam uma remuneração menor. O contrário ocorre nas mesorregiões mais relevantes, como as metropolitanas, em que de fato existem empresas com alto nível tecnológico e consequentemente, trabalhadores com maiores salários.

Na região Norte havia somente 6 mesorregiões relevantes, e destas, 4 se enquadram nas faixas de renda menores. O destaque fica para as mesorregiões Centro Amazonense e Sudeste Paraense que possuíam $46 \%$ e $48 \%$ dos trabalhadores com salários na faixa de 3,01 a 7,0 , respectivamente. No total de trabalhadores das mesorregiões relevante da região, $33 \%$ se enquadravam nas rendas médias menores e $67 \%$ recebem salários maiores.

No Centro-Oeste existiam 11 mesorregiões relevantes, sendo que 8 se enquadravam nas faixas de renda menores. Assim, a renda média predominante era de até 1,5 e de 1,51 a 3,0 salários mínimos, como nas mesorregiões Sudoeste Mato-Grossense (56\% e 41\%), Sudoeste do Mato Grosso do Sul (35\% e 49\%) e Sudeste Mato-Grossense (47\% e 33\%). Algumas mesorregiões se destacavam na faixa de remuneração acima de 7,01, como Leste do Mato Grosso do Sul (56\%) e Sul Goiano (55\%). Vale ressaltar que a mesorregião do Sudoeste Mato-Grossense não possuía nenhum trabalhador com renda média acima de 7,01.

Diferente das outras regiões, nas mesorregiões relevantes do Centro-Oeste a maior parte dos trabalhadores, $58 \%$, se concentravam na faixa de renda de até três salários mínimos, enquanto nas faixas superiores empregavam somente $42 \%$ dos trabalhadores. 
Figura 1 - Renda média dos trabalhadores das indústrias de maior intensidade tecnológica nas mesorregiões industriais relevantes brasileiras em 1995

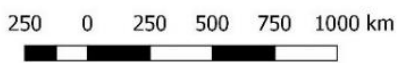

Base cartográfica do IBGE - 2010 Datum: SIRGAS 2000 Fonte dos dados: RAIS - 1995
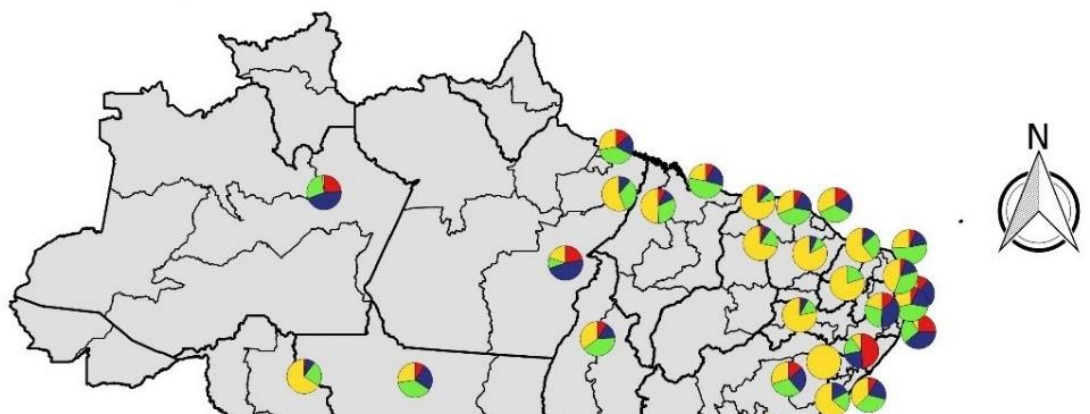

Org - os próprios autores.

As mesorregiões industriais relevantes localizadas nas regiões Sul e Sudeste eram as que possuíam maior número de trabalhadores industriais que recebiam maiores salários. Na região Sul existiam 21 mesorregiões relevantes, sendo que 11 possuíam predominância nas rendas médias menores. A renda média predominante compreendia de 3,01 a 7,0, como Metropolitana de Porto Alegre (39\%), Centro Oriental Paranaense (48\%), Metropolitana de Curitiba (40\%), Norte Catarinense (62\%) e Vale do Itajaí (50\%). A renda média acima de 7,01 salários mínimos também era representativa, como nas mesorregiões Metropolitana de Porto Alegre (35\%), Grande Florianópolis (32\%) e Sudeste Paranaense (38\%). Porém, em que pese uma maior participação relativa dos trabalhadores com salários maiores, havia uma quantidade significativa de trabalhadores na faixa dos menores salários, como nas mesorregiões Centro Oriental RioGrandense, Oeste Catarinense e Sudoeste Paranaense com 50\%, 48\% e 73\% recebendo de 1,51 a 3,0 salários mínimos, respectivamente. Em síntese, nas mesorregiões relevantes da região Sul, $28 \%$ dos trabalhadores recebiam até 3 salários e $72 \%$ acima de 3,01 salários mínimos.

Por fim, o Sudeste possuía 33 mesorregiões relevantes, com apenas 13 se enquadrando nas faixas de renda média menores. Era a região brasileira que tinha maior quantidade de trabalhadores com renda média alta, os salários mínimos de 3,01 a 7,0 e acima de 7,01 predominavam. Nessas faixas de renda destacavam-se mesorregiões como Piracicaba (44 e 44\%), Campinas (39 e 51\%), Metropolitana de São Paulo (34 e 54\%), Metropolitana do Rio de Janeiro (33 e 37\%) e Sul Fluminense (57\% - acima de 7,01). A mesorregião que possuía maior número de trabalhadores recebendo a mais alta renda média (acima de 7,01) do Brasil todo localizava-se no estado de São Paulo, sendo o Vale do Paraíba Paulista, com 74\%. No total 17\% dos trabalhadores das mesorregiões relevantes da região Sudeste apresentavam remuneração de até 3,0 salários mínimos. Já nas faixas de renda maiores, acima de 3,0 salários mínimos, se concentravam $83 \%$ dos trabalhadores. 


\section{INDÚSTRIAS DE MENOR INTENSIDADE TECNOLÓGICA - 1995}

Em relação às indústrias de menor intensidade tecnológica em 1995 verifica-se, por meio do Figura 2, que em todas as regiões brasileiras predominavam as faixas de renda média menores: de até 1,5 e de 1,51 a 3,0 salários mínimos. Em algumas regiões, como Sul e Sudeste, havia o destaque para trabalhadores que recebiam entre 3,01 e 7,0, porém, ainda assim existia a predominância das faixas citadas anteriormente.

Figura 2 - Renda média dos trabalhadores das indústrias de menor intensidade tecnológica nas mesorregiões industriais relevantes brasileiras em 1995

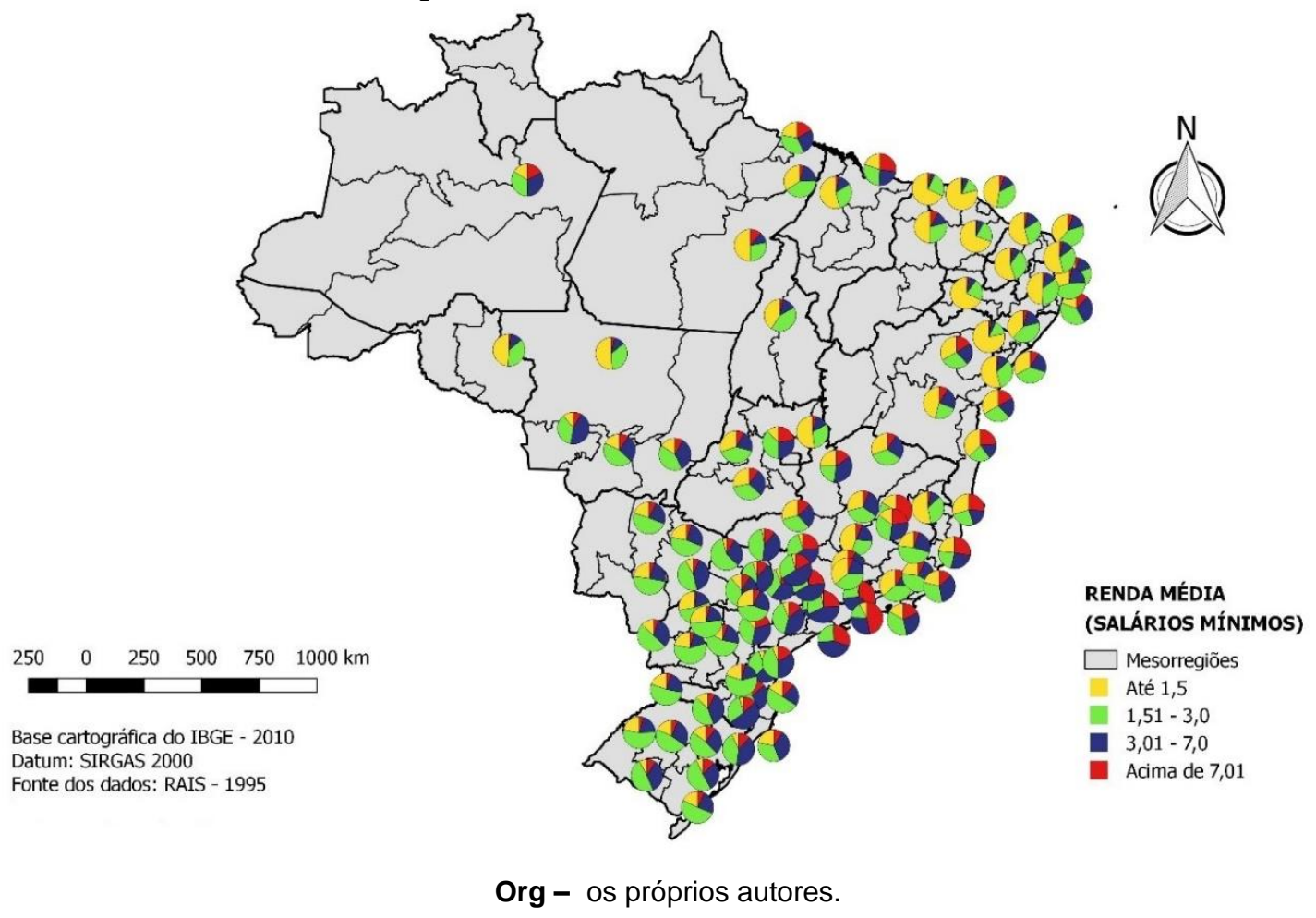

Na região Nordeste destacava-se o predomínio na maioria das mesorregiões da renda média de até 1,5 salários mínimos. As que possuem maior número de trabalhadores nessa faixa eram Agreste Sergipano (78\%), Jaguaribe (69\%) e Norte Cearense (80\%). Ainda assim, em algumas mesorregiões a renda média entre 1,51 a 3,0 também se destacava, como Mata Pernambucana (46\%), Mata Paraibana (44\%) e Metropolitana de Recife (40\%). No total de trabalhadores nordestinos, $71 \%$ recebiam rendas médias menores e apenas $29 \%$ se enquadravam faixas maiores, acima de três salários mínimos.

No Norte brasileiro, a mesorregião do Centro Amazonense possuía representatividade de todas as faixas de renda média, com destaque para a de 1,51 a 3,0 (35\%) e 3,01 a 7,0 (33\%). No restante das mesorregiões, a faixa de até 1,5 salários mínimos era significativa, como no Sudeste Paraense (50\%) e Leste Rondoniense (49\%). Do total de trabalhadores, $65 \%$ concentravam-se nas faixas de renda menores e apenas $35 \%$ nas faixas maiores.

Nas mesorregiões do Centro-Oeste prevaleciam a renda média de 1,51 a 3,0 salários mínimos, como no Leste do Mato Grosso do Sul (47\%) e Centro Norte do Mato Grosso do Sul (49\%). Comparado ao restante de faixas, a de 3,01 a 7,0 também possuía representatividade, como Sudoeste Mato-Grossense (45\%) e Sudeste Mato-Grossense (35\%). Em relação ao total de trabalhadores, $67 \%$ recebiam rendas médias menores e $33 \%$ se enquadravam nas rendas médias maiores.

No Sul do país havia a predominância da renda média de 1,51 a 3,0 salários mínimos, como nas mesorregiões Centro Ocidental Rio-Grandense (54\%), Centro Sul Paranaense (58\%), Grande 
Florianópolis (50\%), Metropolitana de Porto Alegre (51\%), e Sudeste Paranaense (59\%). Em algumas mesorregiões existia destaque da faixa de 3,01 a 7,0, como em Vale do Itajaí (51\%), Norte Catarinense (48\%) e Nordeste Rio-Grandense (40\%). Quanto ao total de trabalhadores, $55 \%$ se enquadravam nas rendas médias menores e $45 \%$ nas maiores.

$\mathrm{Na}$ região Sudeste a renda média variava de acordo com o estado. São Paulo possuía representatividade na faixa de 3,01 a 7,0, como Araraquara (48\%), Metropolitana de São Paulo (44\%) e Piracicaba (44\%). O Rio de Janeiro possuía a segunda mesorregião do Brasil com maior número de trabalhadores recebendo acima de 7,01, sendo no Sul Fluminense, 47\%. Minas Gerais e Espírito Santo possuíam a maioria de suas mesorregiões com rendas médias relativamente distribuídas, apenas o Vale do Rio Doce que se diferenciava possuindo o maior número de empregados com renda média acima de 7,01 do Brasil todo. Em relação ao total de trabalhadores, apenas $41 \%$ recebiam rendas médias menores e $59 \%$ se enquadravam nas faixas de renda maiores.

Em síntese, no ano de 1995, as mesorregiões relevantes localizadas no Sudeste concentravam a maior parte dos trabalhadores da indústria de maior intensidade tecnológica. Em especial, os trabalhadores com melhor remuneração, acima de 3,0 salários mínimos, em que 78,7\% dos mesmos concentravam-se nas mesorregiões do Sudeste. Com importância bem menor aparecem as mesorregiões da região Sul, com 12,9\% dos trabalhadores.

O mesmo ocorre com os trabalhadores da indústria de menor intensidade tecnológica, ou seja, uma concentração nas mesorregiões relevantes do Sudeste, porém em proporção menor. Ainda assim, neste tipo de indústria, $68,9 \%$ dos trabalhadores com remuneração acima de três salários mínimos concentravam-se nas mesorregiões do Sudeste. Com relação aos trabalhadores com menor remuneração a concentração é bem menor, pois, apenas $48 \%$ dos que ganhavam até três salários mínimos concentravam-se nas mesorregiões do Sudeste. Nesta faixa de renda destacavam-se também as mesorregiões relevantes do Sul, com $23,7 \%$ e do Nordeste, com $20,9 \%$.

Nas indústrias de maior intensidade tecnológica, a maior parte dos trabalhadores apresentava remuneração acima de três salários mínimos, com exceção das mesorregiões do Centro-Oeste em que apenas $41,9 \%$ dos trabalhadores recebiam mais de três salários mínimos. Nas demais regiões os trabalhadores melhores remunerados eram sempre em proporção superior a $66 \%$. Destaque para as mesorregiões relevantes do Sudeste, em que $83,1 \%$ dos trabalhadores estavam nesta faixa de remuneração.

Por outro lado, na indústria de menor intensidade tecnológica, existia uma proporção elevada de trabalhadores que recebiam os menores salários. Em especial, nas mesorregiões do Nordeste $(71,2 \%)$, Centro-Oeste $(66,9 \%)$ e Norte $(65,5 \%)$. Somente nas mesorregiões da região Sudeste a proporção de trabalhadores nas faixas acima de três salários mínimos era ligeiramente superior, atingindo $59,3 \%$.

\section{INDÚSTRIAS DE MAIOR INTENSIDADE TECNOLÓGICA - 2015}

Analisando a renda média dos trabalhadores das indústrias brasileiras de maior intensidade tecnológica em 2015, por meio do Figura 3, verifica-se o predomínio das faixas de até 1,5 e de 1,51 a 3,0 salários mínimos. É importante destacar que a representatividade da faixa de acima de 7,01 é muito fraca e em comparação com o restante das faixas, a renda média de 3,01 a 7,0 não é tão presente no território brasileiro.

Na região Nordeste, a faixa de remuneração predominante era a de até 1,5 salários mínimos, como nas mesorregiões Agreste Paraibano (78\%), Agreste Sergipano (70\%) e Sul Cearense $(81 \%)$. O destaque era para a faixa de 1,51 a 3,0, como na Mata Paraibana (49\%), Norte Maranhense (46\%) e Oeste Potiguar (45\%). A faixa de remuneração de 3,01 a 7,0 não possuía tanta representatividade, destacando-se na Metropolitana de Salvador (29\%) e Metropolitana de Recife (21\%). A renda média acima de 7,01 era baixa na região, sendo significativa apenas nas mesorregiões Central Potiguar (68\%), maior de todo o Brasil. Em relação à renda dos trabalhadores, também havia o predomínio das faixas menores com $70 \%$ e apenas $30 \%$ se enquadravam nas faixas maiores, acima de três salários mínimos. 
Figura 3 - Renda média dos trabalhadores das indústrias de maior intensidade tecnológica nas mesorregiões industriais relevantes brasileiras em 2015

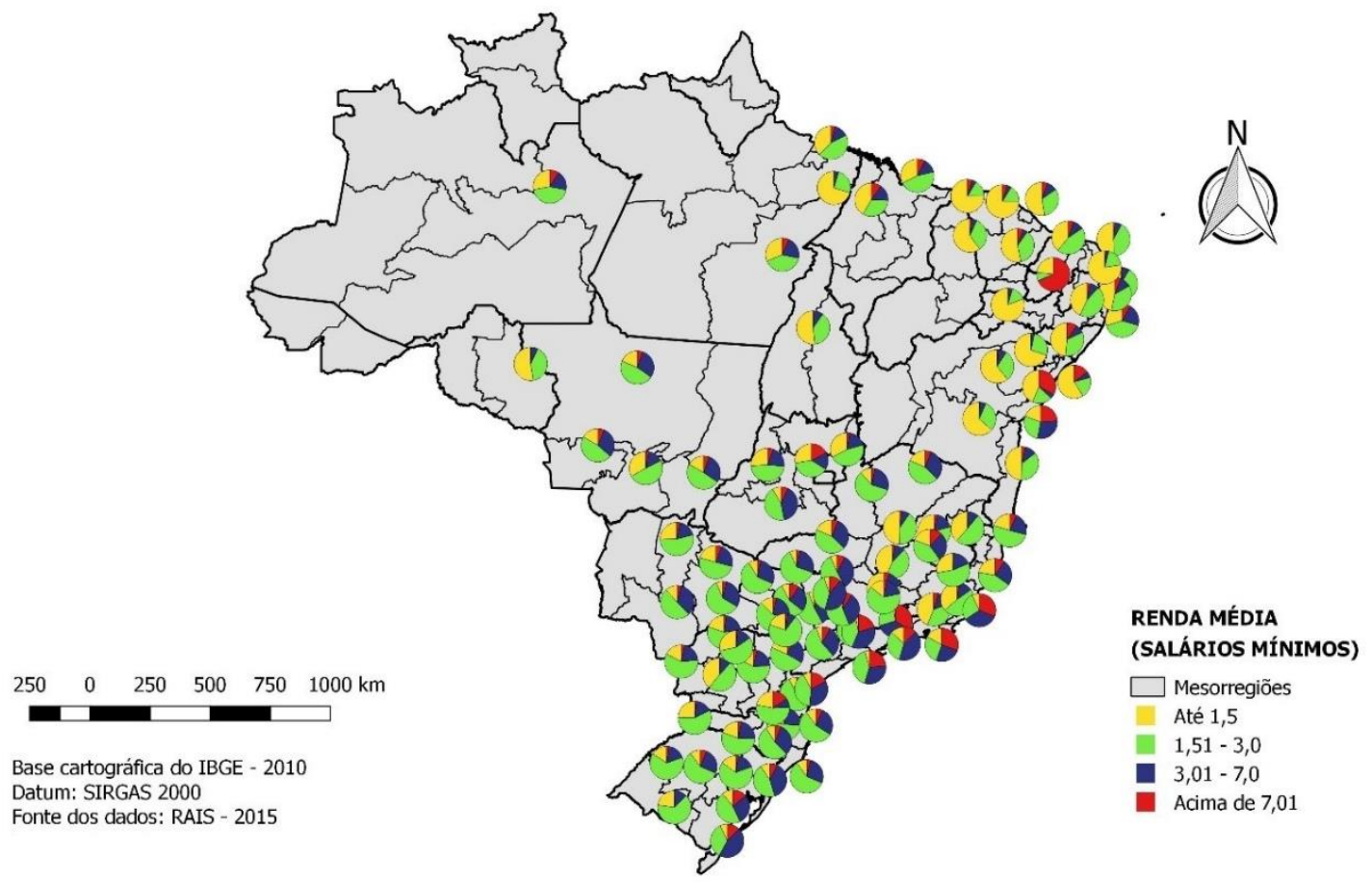

Org.: os próprios autores.

No Norte do Brasil evidenciava-se o predomínio das rendas médias menores, tanto nas mesorregiões quanto para os trabalhadores, apenas $26 \%$ deles se enquadravam nas faixas maiores. A renda média de até 1,5 predominava em mesorregiões como Leste Rondoniense (53\%) e Nordeste Paraense (62\%) e da renda de 1,51 a 3,0 no Centro Amazonense (44\%), Metropolitana de Belém (45\%) e Sudeste Paraense (40\%).

No Centro-Oeste brasileiro predominava a renda média de 1,51 a 3,0 como, por exemplo, nas mesorregiões Centro Goiano (48\%), Centro Norte e Sudoeste de Mato Grosso do Sul (54\%) e Centro Sul Mato-Grossense (49\%). No total de trabalhadores, $67 \%$ se enquadravam nas faixas de renda menores e apenas $33 \%$ recebiam salários maiores.

$\mathrm{Na}$ região Sul, a faixa de 1,51 a 3,0 era predominante em mesorregiões como Centro Ocidental e Oriental Rio-Grandense (65\%), Norte Pioneiro Paranaense (70\%), Sudoeste Rio-Grandense $(65 \%)$ e Sul Catarinense (58\%). Algumas mesorregiões possuíam percentual relevante de trabalhadores na renda média de 3,01 a 7,0 como Metropolitana de Curitiba (35\%), Sudeste RioGrandense (46\%) e Vale do Itajaí (31\%). A faixa acima de 7,01 destacava-se apenas nas mesorregiões Metropolitana de Curitiba (17\%), Metropolitana de Porto Alegre (13\%), Sudeste Paranaense (15\%) e Sudeste Rio-Grandense (12\%), apesar de se caracterizarem como percentuais relativamente baixos. Em relação ao total de trabalhadores, $62 \%$ classificavam-se nas faixas de renda menores e $38 \%$ nas faixas de renda maiores.

No Sudeste brasileiro havia a predominância das faixas de 1,51 a 3,0 e de 3,01 a 7,0, como Bauru (52 e 37\%), Itapetininga (56 e 31\%), Macro Metropolitana Paulista (47 e 34\%), Presidente Prudente (60 e 30\%), Noroeste de Minas (58 e 27\%) e Litoral Norte Espírito-Santense (51 e $22 \%$ ). Era a região que apresentava maior número de trabalhadores com renda média acima de 7,01, como nas mesorregiões Metropolitana do Rio de Janeiro (30\%), Norte Fluminense (31\%) e Vale do Paraíba Paulista (34\%). Quanto ao total de trabalhadores, $51 \%$ se enquadravam nas faixas de renda menores e $49 \%$ nas maiores, sendo a região que possuía maior número de trabalhadores nas faixas maiores. 


\section{INDÚSTRIAS DE MENOR INTENSIDADE TECNOLÓGICA - 2015}

Ao analisar a renda média do pessoal ocupado nas indústrias de menor intensidade tecnológica em 2015, representada na Figura 4, verifica-se o predomínio das faixas menores em todo o território brasileiro, até 1,5 salários mínimos no Norte e Nordeste e de 1,51 a 3,0 no Centro-Sul do país. Com pouca representatividade da faixa de 3,01 a 7,0 e mínima presença da renda média acima de 7,01 salários. Deste modo, as mesorregiões que apresentam significância nesta faixa possuem percentuais baixos, porém relativamente altos se comparados ao restante das mesorregiões, as quais em sua maioria apresentam dados que não ultrapassam $4 \%$.

Figura 4 - Renda média dos trabalhadores das indústrias de menor intensidade tecnológica nas mesorregiões industriais relevantes brasileiras em 2015

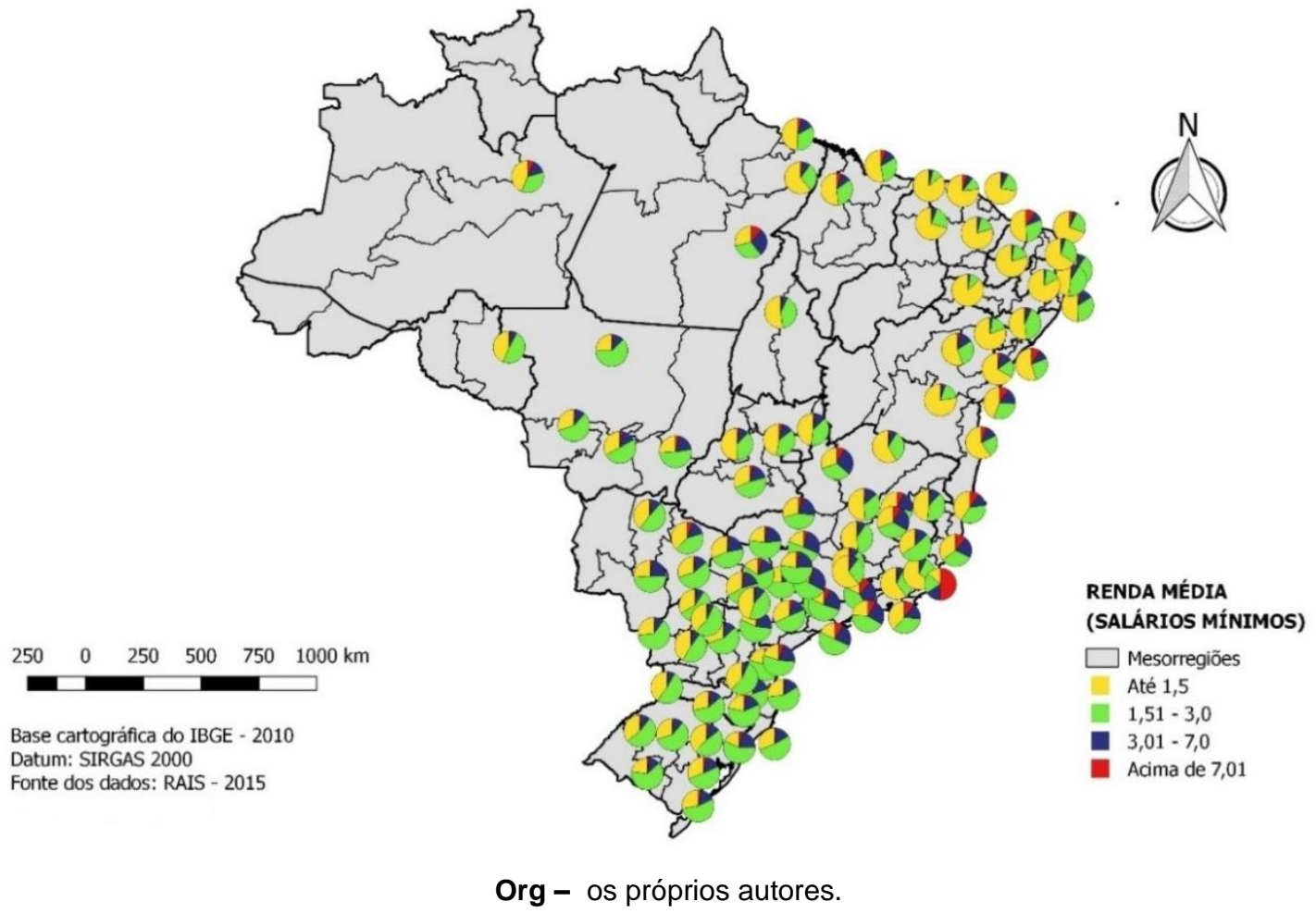

No Nordeste, em todas as mesorregiões, destava-se o predomínio da renda média de até 1,5 salários mínimos, exemplos disso são Agreste Pernambucano (83\%), Agreste Sergipano (80\%), Centro Sul Baiano (77\%), Centro-Norte Piauiense (71\%), Jaguaribe (79\%), Leste Potiguar (69\%), Noroeste Cearense (86\%) e Norte Cearense (76\%). A renda média de 1,51 a 3,0 era significativa em mesorregiões como Leste Alagoano (42\%), Mata Pernambucana (43\%) e Metropolitana de Recife (33\%). Em relação ao total de trabalhadores, $88 \%$ se enquadravam nas faixas de renda menores e apenas $12 \%$ recebiam salários maiores, acima de três salários mínimos.

No Norte Brasileiro havia o predomínio da faixa de até 1,5 salários mínimos, sendo no Centro Amazonense equivalente a $44 \%$, Leste Rondoniense 64\%, Nordeste Paraense $61 \%$ e Metropolitana de Belém $49 \%$. As faixas menores também predominavam no total de trabalhadores, representando $80 \%$.

No Centro-Oeste destacavam-se as faixas de até 1,5 e de 1,51 a 3,0, como, por exemplo, no Centro Goiano (50\% e 34\% respectivamente), Centro Sul Mato-Grossense (33 e 50\%), Distrito Federal (47 e 38\%), Norte Mato-Grossense (25 e 62\%), Sudoeste do Mato Grosso do Sul (26 e $49 \%$ ) e Sul Goiano (32 e 48\%). Deste modo, nota-se que em algumas mesorregiões predominava 
a primeira faixa e em outras predominavaa segunda. No total de trabalhadores, $84 \%$ se enquadravam nas faixas de renda menores e apenas $16 \%$ nas faixas maiores.

No Sul brasileiro predominava a renda média de 1,51 a 3,0, como no Noroeste Rio-Grandense (59\%), Vale do Itajaí (60\%), Oeste Paranaense (63\%) e Sudoeste Rio-Grandense (64\%). A faixa de até 1,5 possuía relevância em mesorregiões como Centro Ocidental Rio-Grandense (36\%), Centro-Sul Paranaense (42\%), e Rio-Grandense (30\%) e Norte Pioneiro Paranaense (46\%) e, deste modo, apresentava maior percentual no Paraná e Rio Grande do Sul. A renda média de 3,01 a 7,0 torna-se relativamente alta em mesorregiões como Centro Oriental Paranaense e Metropolitana de Curitiba (21\%), Grande Florianópolis e Metropolitana de Porto Alegre (15\%) e Vale do Itajaí (16\%). A faixa acima de 7,01 não apresentava percentuais significativos, sendo maior que $4 \%$ apenas no Centro Oriental Paranaense (6\%) e Metropolitana de Curitiba (5\%). Em relação ao total de trabalhadores, $83 \%$ se enquadravam nas faixas de renda média menores e apenas $17 \%$ nas faixas maiores.

$\mathrm{Na}$ região Sudeste predominava na maioria das mesorregiões a faixa de 1,51 a 3,0, como em Araraquara e Bauru (53\%), Marília (65\%), Piracicaba e Sul Espírito-Santense (52\%), Presidente Prudente (56\%) e São José do Rio Preto (54\%). As faixas de até 1,5 e de 3,01 a 7,0 também possuía importância (maior para a primeira) como em Campo das Vertentes (61 e $8 \%$ respectivamente), Central Mineira (51 e 12\%), Norte de Minas (58 e 7\%) e Zona da Mata (60 e $6 \%$ ). Além disso, é a região que apresentava os maiores percentuais da renda média acima de 7,01, destacando Central Espírito-Santense e Vale do Paraíba Paulista (11\%), Litoral Norte Espírito-Santense (10\%), Metropolitana de Belo Horizonte (8\%), de São Paulo (9\%) e do Rio de Janeiro (10\%) e Norte Fluminense (51\%), sendo esta última a que possuía o maior percentual em todo o Brasil. No total de trabalhadores, $73 \%$ recebiam salários menores e $27 \%$ se enquadravam nos maiores.

Em síntese, no ano de 2015, no que se refere às indústrias de maior intensidade tecnológica, as mesorregiões relevantes do Sudeste diminuíram ligeiramente a participação, passando a concentrar $70 \%$ dos trabalhadores na faixa salarial acima de três salários mínimos. As mesorregiões do Sul foram as que apresentaram crescimento mais importante, passando a concentrar $20,2 \%$ destes trabalhadores.

$\mathrm{Na}$ indústria de menor intensidade tecnológica também há uma queda da concentração dos trabalhadores com melhor remuneração nas mesorregiões relevantes do Sudeste, passando a concentrar $61,8 \%$ dos mesmos. Apresentam ligeiro aumento as mesorregiões do Sul, Norte e Centro-Oeste. Com relação aos trabalhadores com menor remuneração as mesorregiões do Sudeste passam a concentrar $43,8 \%$ dos mesmos e as do Sul e Centro-Oeste apresentam pequeno aumento na participação.

Nas indústrias de maior intensidade tecnológica, no ano de 2015, a situação muda radicalmente em relação a 1995, com a maior parte dos trabalhadores se enquadrando nas faixas salariais de até três salários mínimos. As mesorregiões do Sudeste são representativas deste achatamento salarial, pois somente $49,2 \%$ dos trabalhadores da indústria de maior intensidade tecnológica ainda estavam na faixa salarial de mais de três salários mínimos.

Nas indústrias de menor intensidade tecnológica a proporção de trabalhadores nas faixas de renda menores, que já era muito alta em 1995, eleva-se ainda mais, atingindo $89 \%$ nas mesorregiões do Nordeste e, mesmo nas do Sudeste é muito elevada, com $72,6 \%$.

\section{O PROCESSO DE ACHATAMENTO DA REMUNERAÇÃO DOS TRABALHADORES NO PERÍDO DE 1995 A 2015}

Com base nos dados analisados constata-se que os trabalhadores das indústrias de menor intensidade tecnológica possuem renda média menor em relação ao pessoal ocupado das indústrias de maior intensidade que utilizam mais tecnologia, necessitando de maior qualificação profissional e, desta forma, conferem maiores salários a seus empregados.

De acordo com a Tabela 1, o número de trabalhadores aumentou, tanto nas indústrias de menor intensidade tecnológica quanto nas de maior. 
Tabela 1 - Crescimento absoluto e relativo do número de trabalhadores das indústrias de menor e maior intensidade tecnológica nas mesorregiões industriais relevantes brasileiras em 1995 e 2015

\begin{tabular}{ccccccccc}
\hline & \multicolumn{3}{c}{ MENOR INTENSIDADE TECNOLÓGICA } & \multicolumn{3}{c}{ MAIOR INTENSIDADE TECNOLÓGICA } \\
\cline { 2 - 9 } REGIÃO & $\mathbf{1 9 9 5}$ & $\mathbf{2 0 1 5}$ & $\begin{array}{c}\text { CRESC. } \\
\text { ABS. }\end{array}$ & $\%$ & $\mathbf{1 9 9 5}$ & $\mathbf{2 0 1 5}$ & $\begin{array}{c}\text { CRESC. } \\
\text { ABS. }\end{array}$ & $\%$ \\
\hline Nordeste & 522.524 & 902.811 & 380.287 & 73 & 82.709 & 217.990 & 135.281 & 164 \\
$\quad$ Norte & 72.290 & 162.255 & 89.965 & 124 & 39.063 & 78.703 & 39.640 & 101 \\
Centro-Oeste & 124.912 & 358.200 & 233.288 & 187 & 12.464 & 92.844 & 80.380 & 645 \\
Sudeste & 2.093 .821 & 2.627 .485 & 533.664 & 25 & 973.633 & 1.373 .585 & 399.952 & 41 \\
$\quad$ Sul & 764.414 & 1.223 .649 & 459.235 & 60 & 183.716 & 414.922 & 231.206 & 126 \\
\hline TOTAL & 3.577 .961 & 5.274 .400 & 1.696 .439 & 47 & 1.291 .585 & 2.178 .044 & 886.459 & 69 \\
\hline \multicolumn{7}{c}{ Fonte - MTE/RAIS. } \\
\multicolumn{7}{c}{ Org - os próprios autores. }
\end{tabular}

Conforme a Tabela 1, o número de trabalhadores nas indústrias de menor intensidade tecnológica aumentou 47\% de 1995 para 2015, principalmente nas regiões Norte e CentroOeste. Nas indústrias de maior intensidade ocorreu um aumento de $69 \%$, com destaque para as regiões Centro-Oeste e Nordeste.

Em relação aos trabalhadores das indústrias de menor intensidade tecnológica em 1995 e 2015, nas mesorregiões relevantes do Nordeste ocorreu um aumento de $73 \%$, no Norte de $124 \%$, no Sul de $60 \%$, no Sudeste de $25 \%$ e no Centro-Oeste de $187 \%$. Quanto aos trabalhadores das indústrias de maior intensidade, nas mesorregiões relevantes do Nordeste houve um aumento de $164 \%$, no Norte de $101 \%$, no Sul de $41 \%$, no Sudeste de $126 \%$ e no Centro-Oeste de $645 \%$. Deste modo, Centro-Oeste foi a região brasileira que apresentou maior crescimento relativo de trabalhadores, tanto nas indústrias de menor quanto nas de maior intensidade tecnológica.

Apesar das indústrias de maior intensidade tecnológica apresentaram crescimento relativo de trabalhadores superior as de menor entre 1995 e 2015, a quantidade de trabalhadores é maior nestas últimas, considerando que são empresas que empregam menos tecnologias e consequentemente, necessitam de mais funcionários.

É necessário destacar que diversas mesorregiões, principalmente no Norte e Nordeste, apresentaram números significativos de trabalhadores com a maior renda média - acima de 7,01 salários mínimos - em comparação com as outras mesorregiões de sua região brasileira. Porém, ao comparar esse percentual de renda média acima de 7,01 com outras mesorregiões do Brasil, como as do Sul e Sudeste, ele torna-se baixo.

A quantidade de pessoal ocupado aumentou de 1995 para o ano de 2015, já a renda média dos trabalhadores diminuiu. Conforme as tabelas 2 e 3 , a diminuição relativa de trabalhadores nas faixas salariais superiores a três salários mínimos foi generalizada, ou seja, atingiu praticamente todas as regiões, tanto nas indústrias de menor, quanto nas de maior intensidade tecnológica. A única exceção foi a indústria de maior intensidade tecnológica das mesorregiões do CentroOeste que tiveram um pequeno aumento.

Em termos absolutos o aumento dos trabalhadores na faixa de renda de mais de três salários mínimos também foi muito restrita, acontecendo somente nas mesorregiões relevantes do Centro-Oeste, nas indústrias de maior e menor intensidade tecnológica, na indústria de menor intensidade tecnológica da região Norte e nas indústrias de maior intensidade tecnológica das mesorregiões relevantes do Sul do país.

Esta é uma das principais consequências da reestruturação produtiva que se intensificou no país a partir de meados dos anos de 1990. Outro fator de influência é o processo de desconcentração concentrada pelo qual as indústrias brasileiras passam. Na busca pela minimização dos custos as empresas diminuem o salário dos empregados que serão contratados e muitas vezes este é um dos fatores de mobilidade geográfica das mesmas. Porém a desconcentração ocorre principalmente para as mesorregiões do Centro-Sul do país.

Em 1995 as rendas médias maiores dos trabalhadores das indústrias de maior intensidade tecnológica concentravam-se no Sul e Sudeste brasileiro, já as menores rendas predominavam no Nordeste. As indústrias de menor intensidade possuíam rendas médias maiores no Centro- 
Sul e menores também no Nordeste brasileiro. Distinguindo-se das outras regiões, no Norte a remuneração média dos trabalhadores das indústrias de menor intensidade era maior que as de maior intensidade.

As tabelas 2 e 3 apresentam as mudanças que ocorreram com o número de pessoal ocupada em 1995 e 2015.

Tabela 2 - Trabalhadores por faixa de salário das Mesorregiões Industriais Relevantes - 1995

\begin{tabular}{|c|c|c|c|c|c|c|c|c|c|c|}
\hline \multirow[b]{3}{*}{ REGIÕES } & \multicolumn{4}{|c|}{$\begin{array}{l}\text { MAIOR INTENSIDADE } \\
\text { TECNOLÓGICA }\end{array}$} & \multicolumn{4}{|c|}{$\begin{array}{l}\text { MENOR INTENSIDADE } \\
\text { TECNOLÓGICA } \\
\end{array}$} & \multirow{2}{*}{\multicolumn{2}{|c|}{ TOTAL }} \\
\hline & \multicolumn{2}{|c|}{ ATÉ 3 SM } & \multicolumn{2}{|c|}{ MAIS DE 3 SM } & \multicolumn{2}{|c|}{ ATÉ 3 SM } & \multicolumn{2}{|c|}{ MAIS DE 3 SM } & & \\
\hline & TRAB. & $\%$ & TRAB. & $\%$ & TRAB. & $\%$ & TRAB. & $\%$ & TRAB. & $\%$ \\
\hline Centro-oeste & 7.239 & 5,3 & 5.225 & 3,8 & 83.587 & 60,8 & 41.325 & 30,1 & 137.376 & 100,0 \\
\hline Nordeste & 28.060 & 4,6 & 54.649 & 9,0 & 371.968 & 61,5 & 150.556 & 24,9 & 605.233 & 100,0 \\
\hline Norte & 12.921 & 11,6 & 26.142 & 23,5 & 47.318 & 42,5 & 24.972 & 22,4 & 111.353 & 100,0 \\
\hline Sul & 51.216 & 5,4 & 132.500 & 14,0 & 420.016 & 44,3 & 344.398 & 36,3 & 948.130 & 100,0 \\
\hline Sudeste & 164.364 & 5,4 & 809.269 & 26,4 & 853.012 & 27,8 & 1.240 .809 & 40,5 & 3.067 .454 & 100,0 \\
\hline TOTAL & 263.800 & 5,4 & 1.027 .785 & 21,1 & 1.775 .901 & 36,5 & 1.802 .060 & 37,0 & 4.869 .546 & 100,0 \\
\hline
\end{tabular}

Tabela 3 - Trabalhadores por faixa de salário das Mesorregiões Industriais Relevantes - 2015

\begin{tabular}{|c|c|c|c|c|c|c|c|c|c|c|}
\hline \multirow[b]{3}{*}{ REGIÕES } & \multicolumn{4}{|c|}{$\begin{array}{l}\text { MAIOR INTENSIDADE } \\
\text { TECNOLÓGICA }\end{array}$} & \multicolumn{4}{|c|}{$\begin{array}{l}\text { MENOR INTENSIDADE } \\
\text { TECNOLÓGICA } \\
\end{array}$} & \multirow{2}{*}{\multicolumn{2}{|c|}{ TOTAL }} \\
\hline & \multicolumn{2}{|c|}{ ATÉ 3 SM } & \multicolumn{2}{|c|}{$\begin{array}{l}\text { MAIS DE } 3 \\
\text { SM }\end{array}$} & \multicolumn{2}{|c|}{ ATÉ 3 M } & \multicolumn{2}{|c|}{ MAIS DE 3 SM } & & \\
\hline & TRAB. & $\%$ & TRAB. & $\%$ & TRAB. & $\%$ & TRAB. & $\%$ & TRAB. & $\%$ \\
\hline Centro-oeste & 62.295 & 13,8 & 30.549 & 6,8 & 301.324 & 66,8 & 56.876 & 12,6 & 451.044 & 100,0 \\
\hline Nordeste & 122.894 & 12,7 & 41.873 & 4,3 & 716.570 & 73,9 & 88.246 & 9,1 & 969.583 & 100,0 \\
\hline Norte & 57.857 & 24,0 & 20.846 & 8,7 & 129.335 & 53,7 & 32.920 & 13,7 & 240.958 & 100,0 \\
\hline Sul & 307.787 & 15,9 & 190.634 & 9,8 & 1.190 .917 & 61,5 & 247.773 & 12,8 & 1.937 .111 & 100,0 \\
\hline Sudeste & 682.194 & 17,7 & 661.115 & 17,2 & 1.821 .767 & 47,3 & 688.672 & 17,9 & 3.853 .748 & 100,0 \\
\hline TOTAL & 1.233 .027 & 16,5 & 945.017 & 12,7 & 4.159 .913 & 55,8 & 1.114 .487 & 15,0 & 7.452 .444 & 100,0 \\
\hline
\end{tabular}

No ano de 2015 as rendas médias baixas - até 1,5 e de 1,51 a 3,0 - predominam nas indústrias de menor e maior intensidade em todas as regiões do Brasil. Porém, nas indústrias de maior intensidade tecnológica, as rendas médias altas - 3,01 a 7,0 e acima de 7,01 - são mais presentes que nas empresas de menor intensidade, concentrando-se em sua maioria no Sul e Sudeste do país.

Portanto, conclui-se que a desigualdade salarial existe no Brasil, com as rendas médias maiores predominando nas mesorregiões relevantes do Centro-Sul, assim como a maior quantidade de trabalhadores, e que as rendas médias menores se concentram nas mesorregiões relevantes do Norte e Nordeste.

\section{CONSIDERAÇÕES FINAIS}

Diversos processos possuem influência sobre a diferença salarial do pessoal ocupado nas indústrias brasileiras. A reestruturação econômica pela qual o país passou, em que ocorreu a transição do regime de acumulação e modo de regulação fordista para a acumulação flexível, modificou diretamente as relações de trabalho. No primeiro, novas formas institucionais de garantia de crescimento de salário direto foram institucionalizadas, como legislação trabalhista e salário mínimo, e indireto como garantias sociais do Estado-previdência. No segundo, as 
relações de trabalho foram profundamente modificadas e diversos direitos foram perdidos, como os custos com salários indiretos, como previdência e seguridade social.

Deste modo, a reestruturação produtiva resultou na diminuição de grande parte dos salários dos trabalhadores e na perda de direitos essenciais, como previdência e seguridade social, além da insegurança de garantia de emprego. Além da reestruturação, a mobilidade do capital e os processos de concentração e desconcentração que "definem" a localização geográfica das indústrias e as condições de trabalho também alteram os salários de acordo com o local em que a indústria se situa, como evidenciado pela pesquisa, em que os salários das regiões Norte e Nordeste são menores em relação ao restante do país, devido, por exemplo, à concentração de indústrias de maior intensidade tecnológica no Centro-Sul do país.

Portanto, a intensidade tecnológica das indústrias também possui influência na diferença salarial, como comprovado neste trabalho, em que os trabalhadores das indústrias de menor intensidade tecnológica possuem renda média menor em relação ao pessoal ocupado das indústrias de maior intensidade que utilizam mais tecnologia, enquanto as de menor empregam menos tecnologias e, consequentemente, necessitam de mais mão de obra.

Com base nos resultados apresentados pela presente pesquisa, conclui-se que a desigualdade salarial nas indústrias existe no Brasil, que o período em questão foi marcado por uma desconcentração concentrada, em que as mesorregiões de maior crescimento, de maior número de pessoal ocupado e de maiores rendas médias estão localizadas em sua maioria no CentroSul do Brasil. Além disso, nos 20 anos analisados houve uma queda da renda média generalizada, tanto em termos regionais quanto nos ramos industriais de maior ou menor intensidade tecnológica.

\section{REFERÊNCIAS}

AZZONI, Carlos Roberto. Indústria e reversão da polarização no Brasil. 1985. 232f. Tese (Livre-Docência em Economia) - USP - Departamento de Economia e Administração, São Paulo.

BRAGUETO, Claudio Roberto. O Aglomerado Urbano-Industrial de Londrina: sua constituição e dinâmica industrial. 2007. 265f. Tese (Doutorado em Geografia Humana) Faculdade de Filosofia, Letras e Ciências Humanas, Universidade de São Paulo, São Paulo.

BRAGUETO, Claudio Roberto; MARQUES, Ana Carolina dos Santos. Novo mapa do emprego industrial no Brasil: mesorregiões geográficas relevantes. Geografia, Londrina, v. 26, n. 1, p. 92-103, 2017. https://doi.org/10.5433/2447-1747.2017v26n1p92

BRASIL. Ministério do Trabalho e Emprego. RAIS. 2018. Disponível em: <http://bi.mte.gov.br/bgcaged/rais.php>. Acesso em: 25 abr. 2018.

CANO, Wilson. Concentração e desconcentração econômica regional no Brasil: 1970/95. Economia e Sociedade, Campinas, n. 8, p. 101-141, jun. 1997.

DINIZ, Clélio Campolina. A dinâmica regional recente da economia brasileira e suas perspectivas. Brasília: IPEA, 1995.

DINIZ, Clélio Campolina; CROCO, Marco Aurélio. Reestruturação econômica e impacto regional: o novo mapa da indústria brasileira. Nova Economia, Belo Horizonte, v. 6, n. 1, p. 77-103, 1996.

FIRKOWSKI, Olga Lúcia Castreghini. A nova territorialidade da indústria e o aglomerado metropolitano de Curitiba. 2001. 278f. Tese (Doutorado em Geografia Humana) - Faculdade de Filosofia, Letras e Ciências Humanas, Universidade de São Paulo, São Paulo.

FIRKOWSKI, Olga Lúcia Castreghini de Freitas. Considerações sobre as escolas espaciais de análise da indústria no Brasil. Anpege, Fortaleza, n. 2, p. 67-80, 2005. https://doi.org/10.5418/RA2005.0202.0005

HARVEY, D. A condição pós-moderna. Uma pesquisa sobre as origens da mudança cultura. São Paulo: Edições Loyola, 1992. 
LENCIONI, Sandra. Cisão territorial da indústria e integração regional no Estado de São Paulo. In: GONÇALVES, M.F.; BRANDÃO, C.A.; GALVÃO, A.C.F. (org.). Regiões e cidade, cidades nas regiões: o desafio urbano-regional. São Paulo: Ed. UNESP; ANPUR, 2003, p. 465-476

Reestruturação: uma noção fundamental para o estudo das transformações e dinâmicas metropolitanas. In: ENCONTRO DE GEÓGRAFOS DA AMÉRICA LATINA, 6, 1998, Buenos Aires. Anais... Buenos Aires, 1998.

LIPIETZ, A.; LEBORGNE, D. O pós-fordismo e seu espaço. Espaço e Debates, v. 8, n. 25, p. 12-29, 1988.

SANTOS, Eliane Carvalho dos. A reestruturação produtiva - do fordismo à produção flexível no estado de São Paulo. In: SPOSITO, Eliseu Savério (Org.). O novo mapa da indústria no início do século XXI: diferentes paradigmas para a leitura das dinâmicas territoriais do estado de São Paulo. São Paulo: Editora UNESP, 2015, p. 201-245.

SOJA, Edward W. Geografias Pós-Modernas: a reafirmação do espaço na teoria social crítica. Rio de Janeiro, Jorge Zahar Ed., 1993.

TINOCO, Alexandre de Carvalho. Integração ou fragmentação? O impasse gerado pelo fetichismo da desconcentração. Espaço \& Debates, n. 41, p. 46-65, 2001.

Recebido em: 29/06/2018

Aceito para publicação em: 30/01/2019 